\title{
INTERNATIONALISATION TRENDS, INVESTMENT AND LABOUR; ISSUES AND POLICY OPTIONS
}

\author{
Richard Le Heron \\ Massey University
}

Times of restructuring are invariably periods when established frameworks, definitions, categories and models for policy and action are brought into question. New Zealand's late 1980s-90s restructuring era is no exception to this pattern. The conference's title 'Labour, Employment and Work', is made up of words whose meanings are being rapidly refashioned amidst the restructuring, as many norms of social activity are disintegrating and much social experimentation occurs. An important issue, perhaps the most central issue, facing New Zealand researchers in the broad field of social relationships embraced and implied by the terms 'Labour, Employment and Work' (LEW) is the extent to which research can still be conducted using the uncritical application of ideas and research methods traditionally associated with the field. This challenge, of course, applies to all areas of research carried out in turbulent times. Since changes to social relationships are fundamentally at the heart of restructuring, however, it becomes even more important that the fields from which many conceptual, theoretical and analytic categories are derived, be subjected in their own right, to critical and thorough scrutiny. What must be asked then, is the extent to which a a general climate of socio-economic restructuring has extended to a restructuring of ideas about labour, employment and work in the New Zealand context.

In the past decade geographers, sociologists, political scientists, historians, industrial and labour relations analysts and others have contributed to our understanding of the complex historical process of globalisation. In emphasising globalisation researchers are concerned with tendencies towards human interactions and patterns which are potentially global, or in actuality, global in extent or expression. Many historical processes can be considered as contributors towards the organisation of the world as some-kind-of-whole or a singular system. Amongst the more obvious historical examples are those connected with imperialist expansion in the nineteenth century, the rise of socialist states in the twentieth century, the pursuit of free trade as an ideal in both the nineteenth and twentieth centuries, and the contemporary growth of the environment movement. Yet, these examples did not or have not flowed into 'unified', 'singular' 'totalising' movements. This suggests that when we examine globalisation as a tendency we must do so cautiously, knowing precisely the grounds upon which argument and analysis are based.
The concept of globalisation - broad-based theoretical initiative in the wider social sciences - offers particularly useful insight into the forces driving change in the technoeconomic and socio-political spheres of 'developed' and 'developing' nations alike (Allen and Massey, 1989; Peet and Thrift, 1989; Drachte and Gertler, 1991; Clark, McKay, Missen and Webber, 1992). The initiative is primarily emancipatory in its intent, something which signals a potential sympathy if not compatibility and convergence with the interests and motives of many, perhaps all, researchers in the LEW area. One of the principal contributions of the growing political economy literature on globalisation is the way it conceptualises, simultaneously, developments at a variety of levels, from the global to the local. It is this interest in identifying and unpacking the contextuality of ideas about LEW that is revealing 'spatial boundedness' to many frameworks informing current research. New Zealand study on the 'Internationalisation of Enterprises' has found, for instance, that an understanding of the significance of the internationalisation phenomenon and interpretations of its various forms of expression simply cannot be adequately achieved by use of nationally-restricted theoretical and empirical frameworks. Some of the insights of the wider globalisation literature and specifically, the author's New Zealand FoRST funded 'Internationalisation' project are directly pertinent to the LEW field, and are taken up in this paper.

This paper takes the position that changes and trends in LEW in New Zealand are unavoidably entangled in developments whose origins lie, in the main, outside New Zealand. It is further argued that debate about these changes and trends remains largely grounded in conceptual and theoretical frameworks which give insufficient regard to global structural realities and what these realities might mean in particular countries. Rather than rehearse the scope and content of existing LEW frameworks, this paper conceptualises a general process of globalisation centred on developments in the world capitalist accumulation process. (This concept is a narrow interpretation of globalisation, concentrating specifically on developments in the dynamics, form and extent of capital circulation. The theoretically-grounded case put forward in the paper can be abbreviated in the following way: at the end of the twentieth century, the systemic tendencies in capital circulation are now conferring historically different possibilities for global-local interactions.) Because the 
framework is quite abstract it provides purchase on many contemporary developments, serving as a stepping stone into a whole range of theoretically-informed analyses of specific economic, social, cultural and political processes, including those relating to LEW.

\section{Conceptualising Globalisation}

The globalisation perspective is concerned first and foremost with highlighting the nature of global processes, including, not surprisingly because of the strong intellectual input of political economy researchers, the tendency towards a global economy. While the interest in theorising the global accumulation process is strongly emphasised in many literatures, this should not be construed as an argument that the only global forces that count are those connected with capitalism. Nor should it be suggestive of a more diluted position, that the economic sphere, dominated by capitalist forces and imperatives, broadly determines and circumscribes social possibilities (Fagan and Le Heron, forthcoming). Rather, the perspective takes a more accommodating position, recognising the breadth of processes which might coexist or intersect in any territorial context (Britton and Le Heron, 1989). This conceptualisation has the promise of liberating researchers from the narrow canons of particular schools of thought and of encouraging interdisciplinary efforts to establish the nature of restructured social relations characterising late twentieth century life.

A second thread to the globalisation thesis is the necessity of examining, in each context, and in each research situation, the links between the global and local. A single shorthand phrase, global-local interactions, has gained currency to summarise the range of interactions which are potentially connected with particular instances of restructuring. The idea of focusing on interactions operating at different spatial scales flows from the process-based conception of change which underpins theoretical work on globalisation. The conception has at least two interesting advantages: it enables abstract analysis of features which set the stage for interactions, but as well allows concrete local developments to be set in their wider context. Since the process view is concerned with highlighting relationships, any consideration of interactions will also be grounded in relationships. Because interactions of interest inevitably involve people, the relationships of relevance are social relationships. In the broadest of terms, developments in global processes imply, through global-local interactions, changes in social relations, the core subject matter of LEW research. Likewise, local developments, either in isolation, or because they are copied, modified or rejected after scrutiny, affect the expression of global processes. This arises through local-global interactions. Thus, the phrase global-local interactions, is intended to capture the fluidity and dynamics of human activity, in a highly inter-connected world.

Research on capitalism has revealed significant developments in three interrelated areas: (1) the global circulation of capital, (2) the role of the state, especially the national state and (3) the social relations of production and consumption. These are shown diagrammatically in Figure 1. Since fuller details of this conceptualisation are found in Britton, Le Heron and Pawson (1992, 1-16), Fagan (1991) and Fagan and Le Heron (forthcoming) only aspects of immediate pertinence to the LEW problematic are touched upon.

First, Figure 1 treats capitalist globalisation as a complex process which can be helpfully thought about in terms of internationalisation (sketching links of places to other places), the state' srole (defining the scope and possibilities by which place-to-place links might be forged) and the field of social relations, within territories, (which might develop to facilitate links, given the general conditions likely to prevail at a given time).

The definition is thus both a conceptualisation of three relevant domains and a stage for theoretical inquiry into the relevant domains and their connections. The value of the conceptualisation is that it gives a simple way of thinking about how any country (or region) and its activities might be tied into developments elsewhere in the world. The conceptualisation is not intended to convey every type of interconnection, just key relationships which bind together capitalism's expansion on a global scale: the external links of any territory, the way these links are determined, and conditions which are derivative of this context. The conceptualisation is moreover a signpost, showing paths for theoretical investigation. The theoretical literatures associated with internationalisation, the state and state-economy relations have developed in isolation and only recently have been set side-by-side, as the conceptualisation encourages. Further, given the recency of the globalisation perspective a great many specialist literatures may have been missed in the early forays by political-economy researchers into globalisation. By way of a preliminary conclusion, the conceptualisation suggests that globalisation is inherently about geography, especially changing geographies of interdependence.

Second, Figure 1 indicates that both structural and agency de velopments are implicated in globalisation. Thus, the figure incorporates a synthesis albeit in a purely illustrative manner, fundamental changes in structural relationships and the actual outcomes of agents/actors in different contexts and with reference to different contexts. Discussion about internationalisation, for instance, can be couched in abstract terms, referring to tendencies about capital channels in the spheres of trade, finance and production which connect places to each other. This is a theoretical project. Internationalisation can also be phrased in very concrete terms, by reference to specific company activities, which in aggregate, often make up trends about the direction and detail of links amongst places. This can only be clarified through empirical analysis. Intemationalisation is therefore about changing geographies of interaction, built up of many strands including revealed investor behaviour carried out in an institutional context. 
Figure 1. Conceptualising globalisation

GLOBALISATION

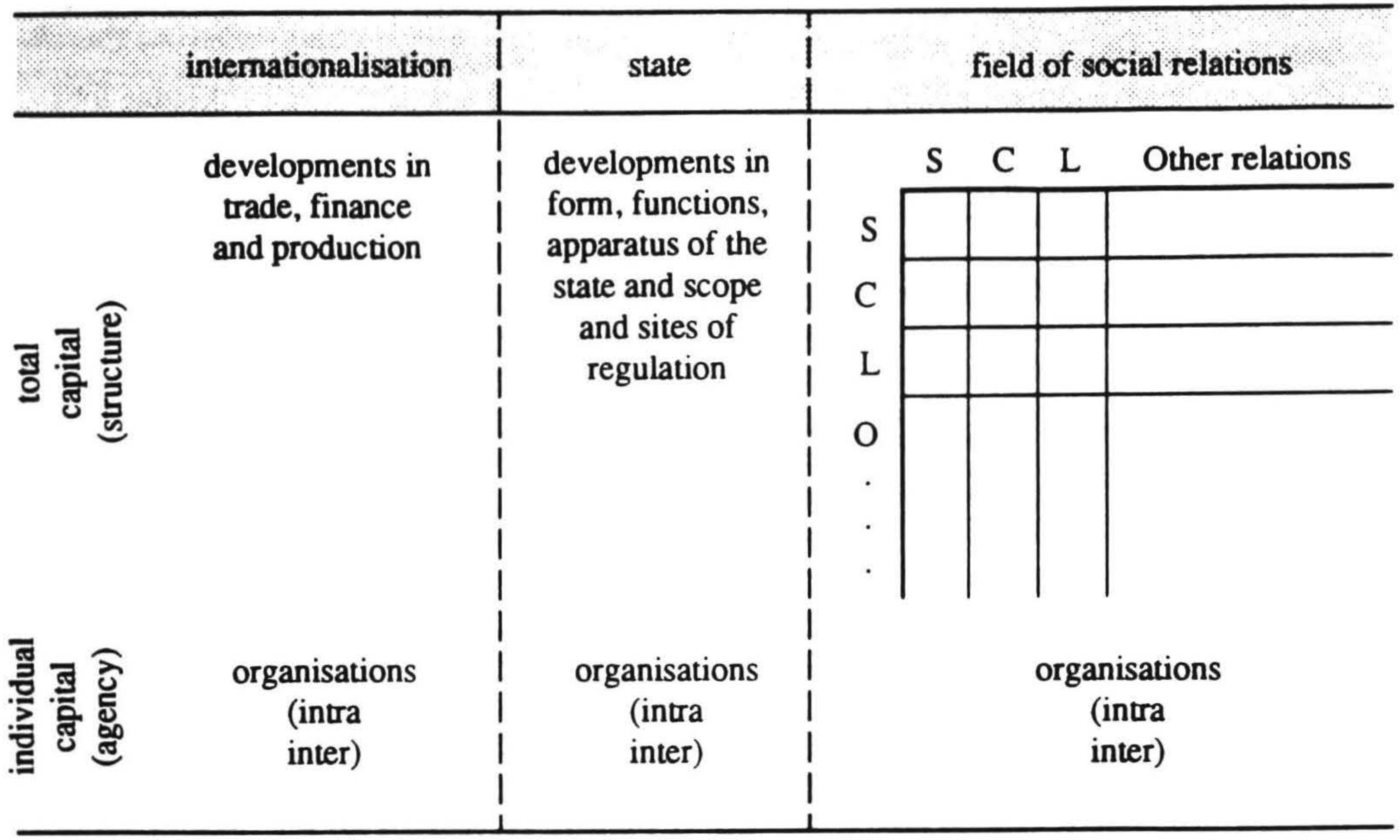

Because this geography of interaction is so diverse, varied and changeable, company to company, and because there is a need to select out relationships which are really fundamental to how places are integrated into the global economy, theoretical analysis helps identify changes of significance. The two research activities of theoretical and empirical work can be arbitrarily separate, though each implies the other. Figure 1 certainly suggests that some heed be given to the risks of misunderstanding resulting from empirical analysis which fails to cast a wide spatial net when assessing the significance of concrete developments.

Third, the figure alerts us to the distinction between what is happening globally and what may be made to happen locally. Global developments represent a benchmark of possibilities; local initiatives may or may not be modelled on overseas experiences. But, very often the latter are copies, and because of this inclination to imitate, in the widest socio-cultural sense, and an apparent imperative, in the narrower sense, a continuing knowledge of global processes is axiomatic in an open and deregulated environment such as New Zealand. Further, local initiatives may be uniquely local, or, as is much more probable, will be hybrids and variants, inspired by examples and knowledge from abroad.

This third conclusion reminds us that globalisation, in whatever form it takes (or example we are studying), is not in itself something tangible or directly measurable. After all, as was stated earlier, globalisation is an abstraction which is intended to help make sense of tendencies, of directions of change, or lack of change. That it is an abstraction should warn us that much effort has to go into conceptualising and theorising the links between the local and the global.

A further feature of the conceptualisation of Figure 1 is that interventions are an integral and continuing feature of globalisation. Following Figure 1, intervention, through the state arena, affects the global link (and hence how rapidly, in what direction, to whose advantage and by which paths internationalisation proceeds at any time) and the mix and character of social relations which might materialise in a country. The diagram should not be seen as implying, because of its global framework, a total dominance of globalising influences, to the exclusion of national and subnational processes. Such a conclusion is an incorrect reading of Figure 1. Rather, the figure simply situates key arenas (the global, national and local), shows how these are inter-connected and acknowledges, through the inclusion of agency, that the outcomes associated with internationalisation, state restructuring and local activity are not predetermined. Indeed, the converse is argued to hold: people, engaging in activities (these are often labelled employment and work) make connections to other people and places, in the context of often poorly perceived structural conditions and constraints.

\section{Capital and Labour Perspectives in Historical Context}

The concem about a knowledge of global-local interactions is probably the strongest message to come out of the globalisation research. Because of this it is worth exploring the implications of the global-local focus a little more. First, the ideal acknowledges that conditions anywhere in the world in the contemporary period of restructuring are 
Table 1 Illustrative schema of perspectives in labour, employment and work research

\section{Capital perspective}

\author{
Skills of labour force \\ Labour upgrade requirements and costs \\ Technological and organisation options \\ for cost reductions/productivity \\ Labour market conditions
}

\section{Labour perspective}

\author{
Employment change \\ Mechanisms creating/deleting jobs \\ Stability of jobs, job control and \\ regulation \\ Training availability and costs, \\ earnings gaps, labour force \\ participation
}

\begin{abstract}
Note: In the long boom the state actively encouraged both national, capital and labour. This resulted in a general convergence of capital and labour interests and a blurring of distinctions which could have been drawn from classical capital or labour positions
\end{abstract}

likely to be highly varied. The contrast with past conditions is crucial. In the earlier long boom, from the late 1940 s to mid 1970s, the state's interventionary practice favoured national capital and labour over either regional or global capital and labour. Indeed, national development models dominated and these were accompanied by a strong and pervasive view of national homogeneity. Moreover, national successes were seen as transferable; the basis of much modernisation and dependency development theory. The instruction of the globalisation perspective is that national models and local models from particular contexts are unlikely to be directly transferable. The reasoning is simple: the underlying conditions behind outcomes will differ widely. This conclusion suggest abandoning the hunt for overseas solutions per se. At the same time it places great stress on understanding conditions in different parts of New Zealand. Whereas the long boom in New Zealand was unpinned by much national development intervention, the interventionary model of the present period favours the expression of global forces, over national influences. This does not mean, however, that global forces will dominate, only that structural conditions, created by intervention, favour the fuller development of global forces and that local developments are likely to reflect such forces. Second, the expectation of the globalisation theorists is that differentiation will be a feature of global-local interactions. This encourages reconsideration of previous guiding ideas, especially critical appraisal of ideas emphasising uniformity of outcomes. Yet, one of the sobering outcomes of New Zealand's restructuring experience is the minimal effort that has gone into conceptualising New Zealand's restructuring outcomes in the context of wider global developments. Notable exceptions are Changing Places in New Zealand (Britton, Le Heron and Pawson, 1992) and Fragmented Societies (Thorns, 1992). Third, many, if not most of our organising frameworks are still what might be termed 'capital-driven'. That is, they focus on tracing and understanding the material expressions, events, forms, conflicts and impacts of capitalistic transformations in our pattems of living.
This bias in our knowledge systems has meant contınuing attempts to find solutions to problems using the assumptions, objectives and lexicon of capitalism. This paper is an example! In the context of the post-1945 long boom of capitalism, a number of research traditions quickly crystallised in the field of LEW. These traditions reflected capital (the most popular) and labour perspectives, each emphasising related topics, but unified by a common interest in capitalistically organised production. Some of the research traditions are briefly illustrated in Table 1.

These traditions were strengthened by the mid-century accord between employers and employees, which conferred a general growth environment. It is not surprising that quantitative research gained supremacy over qualitative studies: the stable growth environment helped solidify assumptions about the continuation of full employment, the growth of industrial factory jobs, sectoral shifts in employment from agriculture into manufacturing and services, the permanence of nuclear households and twoparent family structure, and labour force participation preferences and rates (see Pugliesi, 1991 for a provocative discussion of the industry-bias in LEW research on agriculture). This accounts to a degree for the rise in subdisciplinary areas such as development planning and regional economics with their interests on regional employment change, multiplier analysis and input/out tables. A heavy reliance on census employment statistics and calculations based on aggregate data swung inquiry away from conceptualising and theorising qualitative dimensions of change. For a time census-based studies during the long boom became increasingly constrained by institutionally rigid definitions that 'ruled' how data would be gathered. Morrison (1991) reviews the considerable efforts made by the New Zealand Department of Statistics to accommodate changes in patterns of activity and notes the important role being played by the United Nations in encouraging global changes in census gathering and reporting. Morrison suggests that shifts in the conceptualisation of work and work activity have followed 
both the restructuring of national economies and the pressure for a more realistic recognition of unpaid work undertaken by women.

Behind all definitions, however, are conceptions about the field of study and unless the conceptions of a changing world are being revised to better describe and explain new circumstances and patterns, operational definitions may be found to be very limiting. The asymmetry of LEW research towards the quantitative and about certain aspects of economic growth was thus a by-product of particular structural conditions. When economic conditions unceremoniously changed in the 1980 s, the basis of growth began to alter. Past descriptions and oversimplified explanations neither adequately summarised what was happening in the 1980s nor gave much insight into the whys and hows of change. The questions of the past (and their answers) no longer made much sense. Up to a point, these are historical comments. But the lesson of this recent history is that adequate conceptualisation of the new global order and how it is reshaping our existence and our intellectual tools must be taken seriously. The globalisation literature is fortunately sufficiently informative to ensure there will be a debate in LEW circles about a new research agenda.

\section{Conceptualising Intervention}

With the active promotion of an open market-oriented economy and the dismantling of the national interventionist institutions of the long boom, the greatest challenge to securing stable links into the global economy is now represented by conflict over the nature of intervention. The conflict is actually an amalgam of two strands of conflict: tension over the legitimacy of public versus private intervention and tension centring on the sites and scales of intervention. The globalisation perspective suggests that the long boom featured a steady swing towards public sector intervention at the national level. In contrast, restructuring of the economic and state spheres in New Zealand resulted in a rapid contraction of state involvement away from a stance supportive of capitalist expansion towards one which is only facilitative. The perspective isalso suggestive about the regulatory emphasis in the 1990s. Figure 2 provides a comparison of intervention during the long boom and the restructuring era. Importantly, globalisation research theorises and documents profound changes in the way private sector organisations are integrating their activities on an increasingly global scale (Fagan, 1990a, b; Le Heron, 1990). Global integration cannot be overlooked. It represents the axis around which much interventionary activity will probably centre, partly because some activity will be aimed at facilitating such development while other activity will be resistant in character. The clash over intervention is especially significant for LEW research.

It is helpful to examine evidence on the internationalisation of Australian and New Zealand companies. A descriptive summary of different phases to the recent episode of internationalisation is shown in Figure 3. A number of trends effectively remake the manner in which the major corporates are engaging in the global economy. This development is neither stable nor simple. The amount of change in corporate strategy after the 1987 share market collapse is noteworthy (shown indicatively as Phase II in Figure 3). Importantly, the trends which have emerged since deregulation in New Zealand (and to a lesser extent, Australia) must be seen as developments occurring in the context of very different

Figure 2. Conceptualising intervention

\begin{tabular}{|c|c|c|}
\hline level of intervention & long boom & restructuring crisis \\
\hline nation-state & $\begin{array}{l}\text { protective role } \\
\text { for national } \\
\text { capital and labour }\end{array}$ & $\begin{array}{l}\text { facilitator of } \\
\text { requirements for } \\
\text { global capital }\end{array}$ \\
\hline supra-state & minimal & $\begin{array}{l}\text { setting terms of } \\
\text { political debate and } \\
\text { economic policy }\end{array}$ \\
\hline local & minimal & $\begin{array}{c}\text { forced adaptation } \\
\text { and conciliatory } \\
\text { negotiation? }\end{array}$ \\
\hline
\end{tabular}


Figure 3. Internationationalisation of Australian and New Zealand companies

\begin{tabular}{|c|c|c|}
\hline & trends & features \\
\hline \multirow[t]{2}{*}{ Phase I } & diversification of activity & $\begin{array}{l}\text { reshaping global link } \\
\text { (involving new trade, finance } \\
\text { and production links) }\end{array}$ \\
\hline & $\begin{array}{l}\text { geographic spread of } \\
\text { activity }\end{array}$ & $\begin{array}{l}\text { expanding trans-tasman links } \\
\text { (involving connections to new } \\
\text { places) }\end{array}$ \\
\hline \multirow[t]{3}{*}{ Phase II } & $\begin{array}{l}\text { retreat -to-core } \\
\text { activities }\end{array}$ & $\begin{array}{l}\text { intra-corporate links } \\
\text { altering global ties }\end{array}$ \\
\hline & $\begin{array}{l}\text { geographic restriction } \\
\text { of area of operation }\end{array}$ & $\begin{array}{l}\text { redefinition of trans-tasman } \\
\text { link with New Zealand } \\
\text { equivalent to an 'Australian } \\
\text { state' }\end{array}$ \\
\hline & $\begin{array}{l}\text { job - shedding in total } \\
\text { and regionally }\end{array}$ & \\
\hline
\end{tabular}

state policy regimes. Prior to deregulation, national capital (and labour) were privileged over other capital. Deregulation, as a national policy commitment, meant global capital was inherently favoured. But this did not guarantee that the new opportunities would be suddenly and fully taken up by the better placed globally-oriented or globally-aspirant corporates, or, that less advantaged national and local organisations would not try to compete in the new environment. The evidence of the New Zealand scene, at least for the major corporates, is that they quickly moved into a more 'international mode' but equally quickly found global competition forced further changes to their strategies and operations.

Changes to the interventionary context are thus extremely critical in setting general conditions, and equally critically, not lead to predetermined outcomes. The changes in emphasis of intervention, illustrated by the spatial scale of intervention in Figure 2, must therefore be seen as a trigger for a reconceptualisation of the global link and an empirical search for potentially different forms of interaction. In the case of the major corporates a range of developments are associated with the internationalisation of the corporates (Britton and Le Heron, 1991; Britton, Le Heron and Pawson, 1992). These developments include internal labour force restructuring reducing the size of the corporate labour force, new linkages with small and medium-sized enterprises, different New Zealand head office-activity unit relationships, different connections between Australian headquarters and New Zealand offices, responses to a new labour relations regime (Blunden, 1991; Le Heron, forthcoming).

The strategies of the main company's impact on how it ties into the global economy are pursued. Some LEW consequences follow. Employment change must be discussed as part of employment change in the whole context of a corporation. Discussion of labour and labour force qualities can hardly be confined to New Zealand shores. The meanings attached to tasks inside and outside the corporation, at large and by particular individuals connected with, or formerly connected with the corporation, are altering.

The New Zealand evidence represents only a small and historically specific example of global-local intractions within a particular regional setting. On a world level, different organisational behaviours of TNCs, according to cultural and national background, have been identified. A scrutiny of Japanese foreign direct investment patterns and the associated corporate strategies reveals significant changes in the 1980s and 1990s. Japanese investors are recent entities in the global arena of foreign investment but their global-localisation strategy involves seeking to be as much an insider in overseas markets as a local company, but at the same time still accomplishing the benefits of world-scale operations (Julius, 1990; Edgington, 1991). Japanese TNC organisational structure and corporate strategy have a direct relationship on their behaviour and negotiation strategies in host countries. Moreover, the 
'tetra-polar strategic division of the world' by Japanese TNCs (Edgington, 1991) means Japanese head offices consider each of their world-wide centres and all localised relationships as sources of ideas, products and other resources that can be harnessed to the advantage of the total organisation. These emerging links are likely to impact comprehensively on LEW relations.

The argument in this section has stressed that a reconception of intervention, as part of globalisation, necessitates a rethinking of interactions in the new structural context. While only brief reference has been made to corporate changes they are nonetheless illustrative of major shifts in the fabric of New Zealand's global-nationallocal links and how there are implications for LEW research. The next section looks at the contribution the globalisation literature makes to interpreting developments in the global economy and the strategic interventionary options open in this context.

\section{Revised Capital and Labour Perspectives}

Seen from a globalisation framework, some quite fundamental changes are discemible in the global economy. A wide variety of historical experiences are seen too in different countries as governments adopt different interventionary strategies which affect the intensity and depth of exposure of their territory to global forces. The globalisation framework has something to say on the main directions of global change and on the historical contests over the degree and terms of engagement in the global economy. An interesting literature on international growth regimes points to the heavy involvement of TNCs in the integration of the global economy. The growing integration on a global scale is a feature of different segments of the global economy, eg forestry, finance, fisheries, automobiles, micro-electronics, education, health, tourism, durable foods and fresh fruit and vegetables. In essence, the integration is being cemented by TNCs in the context of a variously porous setting of nation-states. This invites the development of a revised capital perspective (Figure 4), seeking to emphasise local initiatives which are in harmony with global transformations.

Figure 4 highlights the historical connection of New Zealand to earlier and emergent international growth regimes, as well as the fragility (eg automobiles, which virtually disappeared post-deregulation) and the absence of major connections (micro-electronics, which while encouraged in the early 1980 s has only a limited presence). But before this perspective can be fully articulated, more information on the role of the TNCs is needed. For the TNCs one of the biggest difficulties seems to be coordinating development on a new geographic scale, the global (Julius, 1990). The TNC coordination is very dependent on relatively stable but expanding investment environments, that is, international growth regimes. What is the knowledge level in New Zealand about international growth regimes? From the standpoint of nurturing an internationally competitive sector, continuing monitoring of patterns of global integration is essential. Moreover, the knowledge demands are considerable, especially in the newer global growth regimes of tourism, health, education and finance. Unless a great deal is known about the spatiality of these regimes, few sensible New Zealand and local responses can be made. Ignorance about how competitor areas are responding means public policy recommendations at various levels could be flawed and private sector investments based on inadequate information.

If knowledge of international growth regimes represents the ingredients of a revised capital perspective, then the rudiments of a revised labour perspective can also be sketched (Figure 5). Such a perspective recognises that the global context in which businesses operate is vastly different in the 1990 s compared to the relatively stable post-WW II

Figure 4. Revised capital perspective

\begin{tabular}{cll}
\hline integration & \multicolumn{1}{c}{ international growth regimes } \\
\hline $\begin{array}{c}\text { (increasingly on } \\
\text { global scale) }\end{array}$ & \multicolumn{1}{c}{ older } & \multicolumn{1}{c}{ newer } \\
\hline TNCs & $\begin{array}{l}\text { frozen foods } \\
\text { durable foods } \\
\text { forest resources } \\
n\end{array}$ & $\begin{array}{l}\text { fresh fruit and vegetables } \\
\text { education } \\
\text { health } \\
\text { tourism }\end{array}$ \\
\cline { 2 - 3 } & automobile & $\begin{array}{l}\text { micro electronics } \\
\text { coordination }\end{array}$ \\
\hline
\end{tabular}


Figure 5. Revised labour perspective

\begin{tabular}{|c|c|c|}
\hline \multicolumn{3}{|c|}{ environment to achieve employment and social outcomes } \\
\hline & Strategy 1 & Strategy 2 \\
\hline & low capital & living standards \\
\hline goals & $\begin{array}{c}\text { internationally competitive } \\
\text { industries }\end{array}$ & $\begin{array}{l}\text { interventions of industries } \\
\text { in health, housing, } \\
\text { environment, welfare etc }\end{array}$ \\
\hline $\begin{array}{l}\text { worker } \\
\text { qualities }\end{array}$ & superficial training & $\begin{array}{c}\text { education a high } \\
\text { priority }\end{array}$ \\
\hline emphasis & $\begin{array}{c}\text { contractible residuals } \\
\text { of welfare state }\end{array}$ & $\begin{array}{l}\text { social primacy of } \\
\text { 'living standards' } \\
\text { industries }\end{array}$ \\
\hline
\end{tabular}

Note: The 'low capital' and 'living standards' strategies correspond loosely to the 'hard' and 'soft' subschools in the human resources management field.

years. The perspective exposes two broad strategies for dealing locally with global pressures. Strategy 1 , a low capital approach, reduces labour to a social cost which must be contained when striving for international competitiveness. In contrast, Strategy 2 , a living standards and by implication a high capital approach, gives priority to a variety of interventions focusing on living standards outcomes. This black and white characterisation is deliberate. It reveals both extreme positions and the likelihood of tensions over the relative importance and attainment of different goals.

Both Figures 4 and 5 portray different structural realities and options set against such realities. The task ahead for LEW researchers is to conceptualise a research agenda which is sufficiently focused to situate studies in the context of globalisation. All papers at the Conference offered glimpses of responses to globalisation and proactive strategies in a global arena. While there will be much debate about the coverage and content of a research agenda, some preliminary priorities are identified in Table 2 . The conceptualisation reflects the breadth of discussion at the Conference: more than capital and labour (class-based categories) dimensions received attention. Gender and ethnicity represent different starting points and could, for instance, necessitate a restatement of the illustrative foci listed beneath the capital/labour heading (Gibson and Graham, 1991; Pahl, 1988).

\section{Conclusion}

This paper has argued that LEW research efforts should recognise that New Zealand's restructuring era has fundamentally altered New Zealand's external link and its internal conditions. A case has been made to take globalisation debate seriously and to pose different LEW questions. This is hardly a rejection of the field. Indeed, quite the opposite conclusion must be drawn. The categories labour, employment and work are being socially redefined, by complex forces, powered by countless actors. The redefinition is as much about access/non-access, advantage/ disadvantage, reward/non-reward to tasks in the public and private domain. Redefinitions of LEW are bound up with power plays centred on production and consumption possibilities and norms. Capital/labour dynamics, gender

\section{Table 2 Conceptualising a Research Agenda}

\section{Capital/Labour}

Technology and labour processes Labour processes and division of labour Immigration and LEW cultures

Corporate strategy and labour management Tariffs, non-tariff barriers and LEW

Pluriactivity

Casualisation

Enterprise models, tasks, jobs and income 
andethnicity issues are all deeply implicated in any question relating to social tasks. Who might be involved, in what work, employment and labour, how they might participate, to what ends and for what entitlements are urgent concerns for the 1990s in New Zealand. These questions have a global reach; to begin to answer them requires a conceptual shift to integrate the global and local.

\section{Future Research}

At the more pragmatic level of future research directions three research priorities logically stem from a consideration of LEW research in the context of historical processes. These can be briefly phrased as: how might we approach conceptual, theoretical and empirical investigations in the area; what sorts of broad indicators will give fresh insight on the nature of socio-economic restructuring and its implications for LEW; and, what strategies can be put in place to facilitate locally-grounded research. These three concerns, phrased in general terms, are intended as suggestions about how to move forward, by giving sharper direction to research efforts. They also derive directly from a consideration of globalisation tendencies. New interactions, understood from different perspectives encourage and demand noticeable changes in practice, in this case of research. Developments originating outside New Zealand are likely to have some general expression in New Zealand and need to be examined in terms of impacts on people and their relationships to labour, employment and work. Although external pressures may be predominant, local initiatives must be recognised and supported. The systematic monitoring and information collecting function of census and research activity institutionalised as part of nationalism and the nation-state in the twentieth century can thus be modified, to emphasise global-local interactions, as seen through different lenses.

Priority one is a research programme on LEW, the scope, content and protocol of which could originate from workshops involving participants committed toestablishing a dialogue over research aims, research practice, communication of research findings and soon. This would of necessity involve researchers with different perspectives but especially those also interested in moving from debate per se into discussion about negotiating the basis of a distinctly new research programme attuned to structural developments and aspirations and expectations of actors. Little more can (or should) be said about this suggestion other than that one appropriate mechanism to expedite what would be a bold step in social sciences research is the Foundation for Research Science and Technology (FoRST).

Priority two-a focus on LEW experiences of individuals - represents a significant gap which has been highlighted in recent years by feminist research in particular. The feminist critique rejects the household and organisations as the key units of analysis because too often they become black boxes hiding power-plays centred on gender. Instead, feminist theory stresses that gender, like class and race, is a basic building block of social organisation and that gender relations, which are socially constructed and historically variable relationships and meanings through which sex differences become socially significant, typically sustain systems of power capable of shaping the structural capacities of persons. Life profiles of school leavers forms one strategy to explore work, employment and labour experiences in New Zealand's structural setting.

Priority three - ways of sustaining community-informed and community-initiated labour, employment and work are already being pursued by Maori. Two pioneer studies (Mahi Awatea, in Hastings [a FoRST funded project] and Ka Awatea in Hokiangia [a MAF assisted project]) indicate something of this pattern of research: self-definition at the community-level of researchers, retention of findings at the local-level, group empowerment to use information from research, and so on. This style of research cuts across conventional boundaries of public good research (in the sense of wide access or dissemination), though it is still a public good, through the process of its origination and the absence of alternative channels to create local knowledge.

To go any further in outlining details of the second and third priority areas would be to step back into 'old' categories. What we confer on ourselves and future generations in terms of LEW opportunities depends on informed-responses now. Priority one thus takes an even greater strategic importance.

\section{Acknowledgements}

The support of the Foundation or Research, Science and Technology for conceptual and theoretical research into internationalisation is gratefully acknowledged. Discussions with and suggestions from Mike Roche, Phil Morrison and Brian Easton helped shape the final form of the paper. Their input is greatly appreciated. The interpretation presented in the paper also benefits from the general discussion sessions interspersed throughout the Conference programme. Olive Harris word processed the paper and tables and Karen Puklowski prepared the figures.

\section{References}

Allen, J. and D. Massey (eds) 1989 The Economy in Question Sage and Open University, London

Blunden, G. 1992 The workers In Britton, S., Le Heron, R., and E. Pawson (eds) Changing places in New Zealand. A geographyof restructuring New Zealand Geographical Society, Christchurch, 70-90

Britton, S. and R. Le Heron 1987 Regions and restructuring in New Zealand: issues and questions in the 1980s New Zealand Geographer 43: 129-39

Britton, S. and R. Le Heron 1991 Capital, labour and state relations in the analysis of enterprises and restructuring: an Australasian debate Australian Geographical Studies 29: 285-312 
Britton, S., Le Heron, R. and E. Pawson (eds) 1992 Changing places in New Zealand. A geography of restructuring New Zealand Geographical Society, Christchurch

Clark, G.L., McKay, J., Missen, G. and M. Webber 1992 Objections to economic restructuring and the strategies of coercion: an analytical evaluation of policies and practices in Australia and the United States Economic Geography 68: 43-59

Drachte, D. and M.S. Gertler (eds) 1991 The New Era of Global Competition: State Policy and Market Power McGill-Queen's University Press, Montreal

Edgington, D.W. 1990 Japanese business down under Routledge, London

Fagan, R. 1990a Elders IXL Ltd: Finance capital and the geography of corporate restructuring Environment and Planning A 22: 647-666

Fagan, R. 1990b The restructuring of Elders IXL Ltd: finance and the global shift Australian Geographer 21: $90-92$

Fagan, R. and D. Bryan 1991 Australia and the changing global economy: background to social inequality in the 1990s In O'Leary, J. and R. Sharp (eds) Inequality in Australia William Heinemann Australia, Melbourne, 7-31

Fagan, R.H. and R.B. Le Heron Reinterpreting the geography of accumulation: the global shift and local restructuring Environment and Planning $D$ Society and Space forthcoming

Gibson, K. and J. Graham 1992 Rethinking class in industrial geography: creating a space for an alternative politics of class Economic Geography 68: $109-127$

Julius, D. 1990 Global Companies and Public Policy Royal Institute of International Affairs, Pinter, London

Le Heron, R.B. 1990 Goodman Fielder Wattie Ltd: internationalisation and performance In de Smit, M. and E. Wever (eds) The corporate firm in the changing world economy Routledge, Chapman and Hall, Andover, Hants, 100-119

Le Heron, R. Corporate raiders and industrial restructuring: the case of Brierley Investments Ltd In Schamp, E. and G. Linge (eds) Finance, Industry and Industrial Change Walter de Gruyter, Berlin, forthcoming

Le Heron, R., Roche, M., Johnston, T. and S. Bowler 1991 Pluriactivity in New Zealand's agro- commodity chains Proceedings Rural Economy and Society Section, Sociological of Aotearoa (NZ) Conference, Agribusiness andEconomics Research Unit, Lincoln University, Discussion Paper No. 129, 41-55

Morrison, P.S. 1991 Changes or continuity in the census? Problems of comparability in the New Zealand census New Zealand Population Review 17(1):440

Pahl, R.E. (ed) 1988 Epilogue: on work In Pahl, R.E. On Work: Historical, Comparative and Theoretical Approaches Basil Blackwell, Oxford 743-752

Peet, R. and N. Thrift (eds) 1989 New Models in Geography Unwin Hyman, London

Pugliese, E. 1991 Agriculture and new division of labor in Friedland, W.H., Busch, L., Buttel, F.H. and A.P. Rudy (eds) Towards a new political economy of agriculture Westview Press, Boulder, Colorado, $137-150$

Thorns, D.C. 1992 Fragmented societies? A comparative analysis of regional and urban development Routledge, London 